\title{
Accuracy of the Simplified Version of the Global Risk Score in Detecting Cardiovascular Risk in Women from Quilombola Communities in the State of Alagoas, Brazil
}

Andressa Lima Cavalcante ${ }^{\circledR}$ and Haroldo da Silva Ferreira ${ }^{\circledR}$

Faculty of Nutrition of the Federal University of Alagoas, Maceió, AL - Brazil

Abstract

Background: Cardiovascular risk (CVR) monitoring is important for defining preventive actions against cardiovascular disease; this condition prevails more intensely in scenarios with less infrastructure such as African descent communities. The Framingham Risk Score (FRS) and the Global Risk Score (GRS) have been used in Brazil for CVR monitoring based on scales of points for certain risk factors. Among these, hypercholesterolemia and low high-density lipoprotein cholesterol require tests not always available in primary care. An alternative would be the simplified GRS (sGRS), in which these tests are replaced by the body mass index $\left(\mathrm{kg} / \mathrm{m}^{2}\right)$.

Objective: To determine the accuracy of the sGRS in estimating CVR in African descent women (quilombolas) from Alagoas.

Methods: This is a cross-sectional study with a representative sample ( $n=1015)$ of women from African descent communities in Alagoas. GRS, sGRS, and FRS consisted in the sum of points obtained according to their respective scales. Receiver operating characteristic curves were used to compare the accuracy of these instruments as CVR predictors, assuming the GRS as reference. Statistical significance was assumed when $\mathrm{p}<0.05$.

Results: The prevalence of high CVR assessed with the GRS or sGRS was similar (20.1\% vs. 20.7\%; p>0.05) and higher than that found with the FRS (4.5\%; $<<0.001)$. Considering the area under the curve (AUC), the sGRS had a higher discriminatory power (AUC=0.98; 95\%CI: 0.98-0.99) than the FRS (AUC=0.91; 95\%CI: 0.90-0.93).

Conclusion: Among black women living in regions with less infrastructure, the sGRS produced similar results to the GRS, with greater operational simplicity.

Keywords: Cardiovascular Diseases; Risk Factors; Epidemiology; African Continental Ancestry Group.

\section{Introduction}

Cardiovascular diseases (CVD) are currently the leading cause of death in Brazil and worldwide, justifying the implementation of prevention measures against this public health problem. In this sense, cardiovascular risk (CVR) monitoring allows the establishment of priorities among activities that focus on the CVD problem, assisting in the definition of practices and prognostic analyses. Several algorithms and scores are used to assess CVR, but none have been validated for the Brazilian population, even less so for the country's black population. ${ }^{1,2}$ Therefore, there is no consensus on which procedure would be the most appropriate for this purpose.

The Brazilian Ministry of Health has recommended the Framingham Risk Score (FRS), which is intended to estimate CVR for the most severe forms of coronary artery

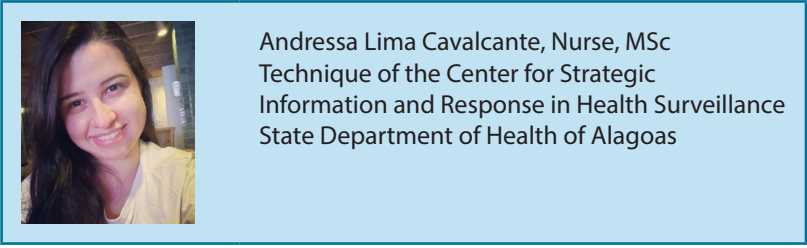


disease (CAD). The Brazilian Society of Cardiology has recommended the Global Risk Score (GRS) to verify the 10 -year risk of developing any atherosclerotic disease events. $^{2}$

Both the FRS and GRS calculations require total cholesterol (TC) and high-density lipoprotein (HDL) data from patients, which are not always available in lowinfrastructure settings. However, a simplified version of the GRS replaces these biochemical data with the body mass index (BMI). The simplified GRS (sGRS), by using measures that are easier to obtain, could thus be a better alternative for use in basic health units. ${ }^{3}$

All these instruments (FRS, GRS, and sGRS) derive from the Framingham Heart Study and are based on the synergism between risk factors for CVD. Therefore, their use is intended to estimate the risk of developing cardiovascular events. ${ }^{3,4}$

CVD affects individuals from lower-income populations more severely since they are more exposed to the different risk factors. In Brazil, the black population and particularly the quilombola population, due to institutional racism, remains historically at lower socioeconomic levels; this situation increases risks associated with CVD. ${ }^{5}$

Given the absence of studies on the accuracy of CVR indicators for the Brazilian population, especially for the black population, this study aimed to investigate the accuracy of the FRS and sGRS, using the GRS as reference. Additionally, we described the prevalence of risk factors for CVD in quilombola women from Alagoas.

\section{Methods}

This work is part of the project entitled II Diagnóstico de saúde e Segurança Alimentar e Nutricional das famílias das comunidades remanescentes dos quilombos do estado de Alagoas, approved by the Research Ethics Committee of Universidade Federal de Alagoas (CAAE No. 33527214.0.0000.5013).

This is a cross-sectional study; data collection was performed from April 2017 to January 2018. The prevalence of high CVR in quilombola communities was considered as the variable of interest to estimate sample size. Since no previous studies had been conducted in Alagoas, the $6 \%$ prevalence found in the state of Maranhão was used. ${ }^{6}$ In 2015, around 6465 families were living in quilombola communities in Alagoas. Assuming that each family had one female member, 6465 women were the universe of interest of this research. ${ }^{7}$ Using the StatCalc tool of Epi Info® 7.2.1.0 and admitting a sampling error of $1.5 \%$ for a $95 \%$ confidence interval (CI), 861 women would be required for this study. In order to compensate for possible sample losses, this number was increased by $10 \%$, totaling 948 women.

In order to achieve this sample number, we randomly chose 34 out of the 68 existing quilombola communities. Women aged between 19 and 59 years from all households in the selected communities were eligible for the study. When there were 2 or more women in the same household, the participating woman was randomly defined. Exclusion criteria were being pregnant or in puerperium, having ingested alcoholic beverages in the last 24 hours, and presenting evident anatomical alterations.

Data collection was performed by interviewers who were properly trained for executing their activities, which occurred under constant supervision. The pilot study used to standardize procedures and test instruments took place before the fieldwork began and was conducted in a community that was not selected for the main study.

Data were collected through interviews using structured forms during home visits. Blood pressure and anthropometric measurements were also obtained. Subsequently, the women were referred to a previously defined place in the community for biochemical tests.

The following variables were obtained for the socioeconomic and demographic characterization of our sample: self-reported skin color (black/brown; other); age group (19 to $39.9 ; 40$ to $49.9 ; \geq 50$ years); education $(<4 ; \geq 4$ years of study); marital status (single; stable relationship; widowed/separated); occupation (not working; farming; other); social class $^{8}(B+C$; $D+E$; there were no families in class A); participation in the Bolsa Família Program (yes; no); and classification according to the Brazilian Food Insecurity Scale (EBIA), which classifies families as being in situations of mild, moderate, or severe food insecurity. ${ }^{9}$

Regarding health and lifestyle variables, the following conditions were defined: optimal blood pressure (BP), normal BP, prehypertension, and hypertension stages I, II, and III; normoglycemia, pre-diabetes mellitus, and diabetes mellitus (DM); smoking; low body weight, eutrophic, overweight, and obesity grades I, II, and III.

Optimal BP was defined by systolic blood pressure (SBP) $<120 \mathrm{mmHg}$ and diastolic blood pressure (DBP) < 80 mmHg; normal BP was considered as: SBP 120-129 $\mathrm{mmHg}$ and DBP 80-84 $\mathrm{mmHg}$; prehypertension: SBP 130-139 mmHg and/or DBP 85-89 mmHg; systemic 
arterial hypertension (SAH) : SBP $\geq 140 \mathrm{mmHg}$ and/or DBP $\geq 90 \mathrm{mmHg}$ or when the use of antihypertensive medications was reported; stage I SAH: SBP 140-159 $\mathrm{mmHg}$ and/or DBP 90-99 mmHg; stage II SAH: SBP 160-179 mmHg and DBP 100-109 mmHg; stage III SAH: $\mathrm{SBP} \geq 180 \mathrm{mmHg}$ and DBP $\geq 110 \mathrm{mmHg} .{ }^{1}$ SBP and DBP measurements were performed in duplicates, according to the Brazilian Guidelines of Hypertension. ${ }^{1}$ An Omron ${ }^{\circledR}$ Hem-7200 portable equipment was used, being periodically calibrated according to the manufacturer's recommendations. If differences greater than $20 \mathrm{mmHg}$ were observed between the 2 measurements, a third measurement was performed and the most discrepant result was disregarded. The mean of the 2 valid measurements was used in the analysis.

Prediabetes and DM were defined by glycated hemoglobin (HbA1c) levels between 5.7\% and 6.4\% and $\geq 6.5 \%$, in that order. ${ }^{10}$ Hypercholesterolemia, hypertriglyceridemia, and low high-density lipoprotein cholesterol (HDL-c) were determined by the following conditions (mg/dL): low-density lipoprotein (LDL) $\geq 160$, triglycerides $\geq 175$, and $\mathrm{HDL}<50$, respectively. ${ }^{11}$ Dyslipidemia was designated when at least one of these lipid profile alterations was found.

In addition to the biochemical reference values, the use of hypoglycemic drugs or medications to control lipid alterations was also a criterion for defining these conditions.

TC, HDL, and $\mathrm{HbA1c}$ measurements were performed using a drop of blood obtained by puncturing the digital pulp, regardless of fasting. ${ }^{12}$ These determinations were performed using an Alere Cholestech LDX® System and, in the case of $\mathrm{HbA1C}$, an Alere NycoCard Reader II®, with their respective analysis cassettes.

Smoking was identified as the consumption of tobacco products in the last 3 months and assessed through the Alcohol, Smoking, and Substance Involvement Screening Test (ASSIST), validated for the Brazilian population. ${ }^{13}$

Nutritional status classifications were based on the BMI according to the following categories ${ }^{14}$ : underweight $\left(<18.5 \mathrm{~kg} / \mathrm{m}^{2}\right)$; eutrophic $\left(18.5-24.9 \mathrm{~kg} / \mathrm{m}^{2}\right)$; overweight $\left(25-29.9 \mathrm{~kg} / \mathrm{m}^{2}\right)$; obesity grade I (30-34.9 $\left.\mathrm{kg} / \mathrm{m}^{2}\right)$; obesity grade II (35-39.9 kg/m²); and obesity grade III ( $\geq 40$ $\left.\mathrm{kg} / \mathrm{m}^{2}\right)$. The weight and height of the participant were measured for calculating the BMI. Body mass was obtained using a digital scale (model 813, Seca®) with a $200 \mathrm{~kg}$ capacity. A portable stadiometer (model 213, Seca®) was used to measure the participants' height.
The GRS was used as reference for evaluating the accuracy of FRS and sGRS in predicting CVR. The GRS is determined by attributing points to age, waist circumference, HDL, systolic blood pressure, smoking, and DM variables, as shown in the table presented in the original publication. ${ }^{3}$ The CVR was classified as follows: $\leq 8$ points (low risk); 9 to 12 points (intermediate risk); and $\geq 13$ points (high risk). ${ }^{2}$

The FRS was proposed in 2001 aiming to identify individuals at high risk for atherogenesis and those who were more likely to develop severe forms of CAD when the atherosclerosis process was already established. ${ }^{15,16}$ Variables constituting the FRS are age, TC, HDL, smoking, SBP, and use of antihypertensive medication; our scores were established as presented in the original publication. ${ }^{4}$ The FRS was classified as follows: $\leq 19$ points (low risk); 20 to 22 points (intermediate risk); and $\geq 23$ points (high risk). ${ }^{17}$ This classification was proposed by the Brazilian Ministry of Health and favors specificity over sensitivity. In order to avoid this problem, in this study the sum of "intermediate risk" and "high risk" conditions was regarded as high CVR.

As mentioned previously, the sGRS is a simplification in which the procedures of the original GRS were maintained, but TC and HDL data were replaced by the BMI. ${ }^{3}$

\section{Statistical analysis}

Data entry was performed by independent double entry on forms generated by Epi Info® 7.2.1.0. Databases were compared to identify and correct typing errors.

A descriptive analysis was performed on the prevalence of high CVR according to the 3 protocols (GRS, sGRS, and FRS), demographic aspects, socioeconomic status, and health conditions. The measure of association was the prevalence ratio (PR) and its respective 95\% CIs, calculated by the Poisson regression with robust variance adjustment.

The receiver operating characteristic (ROC) curve was used to evaluate the accuracy of sGRS and FRS as predictors of CVR using the GRS as reference. Areas under the curve (AUCs) were calculated for each of the evaluated scores using the DeLong test. The Youden index $(\mathrm{J})$ was calculated using the formula $\mathrm{J}=$ (sensitivity + specificity) -1 to define the best cut-off points (CPs), which considered the highest value of J. Subsequently, sensitivity and specificity were compared according to the best CPs or the originally proposed ones. 
Statistical analyses were performed using Stata ${ }^{\circledR} 12.0$ and, in all situations, statistical significance was assumed when $\mathrm{p}<0.05$.

\section{Results}

Our sample consisted of 1015 women. Most of them had black or brown skin, 4 or more years of study, a stable marital relationship, belonged to the lowest economic class, were in a situation of food insecurity, and were contemplated by the Bolsa Família Program. Other sociodemographic characteristics are presented in Table 1.

Table 1 also shows the prevalence of cardiovascular risk factors. A total of $22.6 \%$ women had hypertension, $25.1 \%$ had DM, and $66.8 \%$ were overweight $(30.3 \%$ were obese). The most prevalent lipid alteration was low HDL, followed by hypertriglyceridemia and hypercholesterolemia.

The prevalence of high CVR according to the GRS was $20.1 \%$, which was similar to what was found with the sGRS $(20.7 \%)$ and much higher than the number observed when using the FRS (4.5\%), even when this latter classification grouped "intermediate risk" cases together with the "high risk" category.

We observed a strong association between high CVR and risk factor categories (Table 2). The prevalence of this outcome showed increments ranging from 7.5 to 13.1 times in women presenting SAH stages I to III, respectively. Women with DM had a CVR almost 6 times higher than that of women without this metabolic alteration. Women with stage III obesity had an approximately 3 times higher CVR when compared with eutrophic women. Similar associations also occurred for hypercholesterolemia, hypertriglyceridemia, low HDL, and smoking. Women aged 40 to 49.9 years and those aged 50 or older had frequencies of the outcome of interest that were around 10 and 30 times higher, respectively, than that found in those under 40 years old.

As shown in Figure 1, scales resulting from the FRS and sGRS showed excellent performance in predicting cardiovascular risk (AUC > 0.9; $\mathrm{p}<0.001$ ). However, the sGRS showed a higher discriminatory power than the FRS.

Table 3 shows the best CPs found in this study, with a higher accuracy than that obtained with the originally proposed CPs, particularly for the FRS. The CP of 20, which defines intermediate- and high-risk conditions, presented a sensitivity of only $18.6 \%$, with a very high specificity (99.0\%). Using the CP of 9 , established by the highest $\mathrm{J}$ index, sensitivity and specificity reached $98.0 \%$ and $69.0 \%$, respectively. The prevalence of high CVR, with this change in $\mathrm{CP}$, increased from $4.5 \%$ to $44.4 \%$. Regarding the sGRS, when the CP for high CVR (CP $\geq 13.0$ ) was changed to the one with the best performance ( $C P \geq 11.0$ ), sensitivity increased from $87.2 \%$ to $97.6 \%$, although with a decrease in specificity (from $96.0 \%$ to $88.5 \%$ ). When considering the best $\mathrm{CP}$, the prevalence of high CVR increased from $20.7 \%$ to $28.8 \%$.

\section{Discussion}

CVDs are currently the leading cause of mortality. Therefore, identifying individuals at higher risk is a critical task in public health to enable the adoption of preventive measures. It is important to have accurate and easy-to-operate tools to perform this identification. The results presented herein showed that the sGRS can be used instead of the GRS without any disadvantage. The latter is considered a more complete index because it includes biochemical data that indicate dyslipidemia, which are replaced by the BMI in the sGRS. The performance of the FRS compared to the GRS, although also satisfactory, was worse than that of the sGRS.

When the proposed CPs are used to discriminate patients at high CVR with the FRS, sensitivity is very low (despite a high specificity), which results in a high number of false negatives; this condition is not appropriate for screening CVR for elaborating preventive actions. In this perspective, the GRS should be used and, in the absence of lipid profile data, the sGRS.

Data routinely obtained in basic health units are used in the sGRS, thus this index can be widely applied even in contexts of poor infrastructure. ${ }^{3}$ Among the information required for the sGRS, only the definition of DM is ideally performed by laboratory tests, which could be an obstacle. However, most Brazilian municipalities have implemented the Blood Glucose Self-Monitoring Program, which provides users with glucose testing supplies. ${ }^{18}$ Moreover, the identification of diabetes can be done by self-reporting or when the patient reports the use of hypoglycemic agents. ${ }^{19}$

The women followed in this study belonged to quilombola communities, which comprise a social group that is specially subjected to social inequities and survive in a scenario marked by a low socioeconomic status, poor environmental conditions, and a high prevalence 
Table 1 - Characterization of demographic, socioeconomic, and health conditions of women from remaining quilombola communities in the state of Alagoas, 2018.

\begin{tabular}{|c|c|c|}
\hline Characteristics & Sample ${ }^{a}$ & n (\%) \\
\hline Self-reported skin color & 1013 & - \\
\hline Black + brown & & $922(91.0)$ \\
\hline Others & & $91(9.0)$ \\
\hline Education (years) & 1011 & - \\
\hline$<4$ & & $369(36.5)$ \\
\hline$\geq 4$ & & $642(63.5)$ \\
\hline Marital status & 1015 & - \\
\hline Single & & $129(12.7)$ \\
\hline Stable relationship & & 799 (78.7) \\
\hline Others (widowed, divorced) & & $87(8.6)$ \\
\hline Social class ${ }^{b}$ & 1015 & - \\
\hline $\mathrm{B}+\mathrm{C}$ & & $59(5.8)$ \\
\hline $\mathrm{D}+\mathrm{E}$ & & $956(94.2)$ \\
\hline Food security $^{c}$ & 1001 & - \\
\hline Food security & & $260(26.0)$ \\
\hline Mild insecurity & & $324(32.4)$ \\
\hline Moderate insecurity & & $241(24.1)$ \\
\hline Severe insecurity & & $176(17.6)$ \\
\hline Food insecurity (all types) & & $741(74.0)$ \\
\hline Contemplated by the Bolsa Família program & 1007 & 741 (73.6) \\
\hline Main occupation & 1007 & - \\
\hline Does not work & & $445(44.2)$ \\
\hline Family farming & & $335(33.3)$ \\
\hline Others ** & & $227(22.5)$ \\
\hline Systemic arterial hypertension ${ }^{\mathrm{d}}$ & 1015 & $229(22.6)$ \\
\hline Diabetes mellitus ${ }^{e}$ & & $254(25.1)$ \\
\hline Excess weight (overweight + obesity; BMI $\geq 25 \mathrm{~kg} / \mathrm{m}^{2}$ ) & & $678(66.8)$ \\
\hline Hypercholesterolemia (LDL $\geq 160 \mathrm{mg} / \mathrm{dL})^{\mathrm{f}}$ & & $102(10.0)$ \\
\hline Hypertriglyceridemia (triglycerides $\geq 175 \mathrm{mg} / \mathrm{dL}$ ) ${ }^{\mathrm{f}}$ & 1014 & $299(29.5)$ \\
\hline Low HDL $(\mathrm{HDL}<50 \mathrm{mg} / \mathrm{dL})^{\mathrm{f}}$ & & $739(72.8)$ \\
\hline CVR classification according to the Global Risk Score (GRS) ${ }^{g}$ & 1015 & - \\
\hline Low & & 646 (63.6) \\
\hline Intermediate & & $165(16.3)$ \\
\hline High & & $204(20.1)$ \\
\hline CVR classification according to the simplified GRS ${ }^{\mathrm{h}}$ & 1015 & - \\
\hline Low & & $652(64.2)$ \\
\hline
\end{tabular}




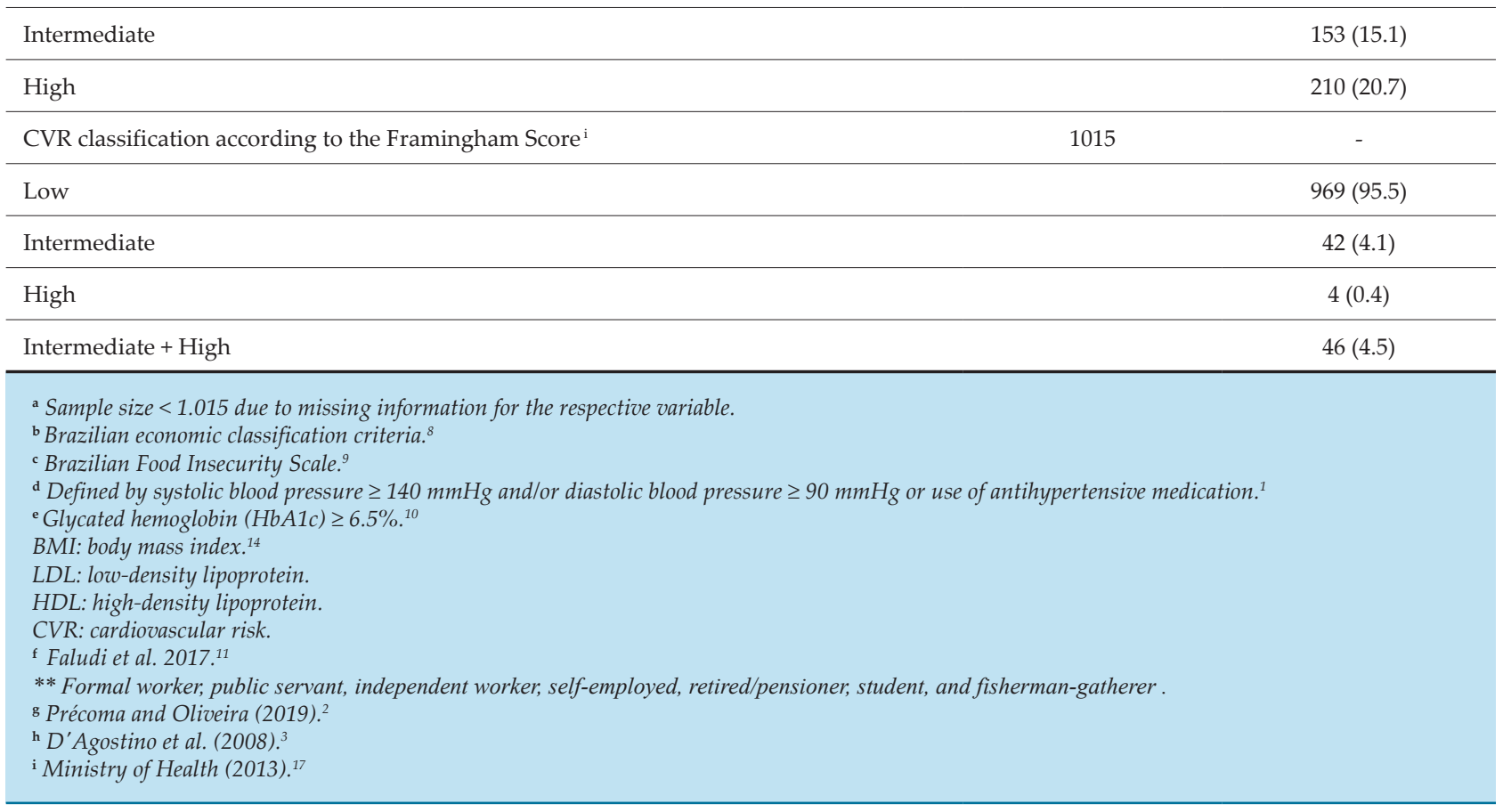

of food insecurity and morbidities related to this context. These characteristics are not exclusive to the quilombola women of Alagoas (who our sample plan attempts to represent), being extended to the entire Afrodescendant Brazilian population..$^{20,21}$

Some studies have shown a differential distribution of aggravations when comparing individuals from the quilombola population with those not from this population. Silva et al..$^{21}$ investigated the prevalence of food insecurity in 21 rural communities located in the northeast region of Brazil, 9 of which were quilombolas. A prevalence of $64.9 \%$ was observed among quilombolas and a prevalence of $42 \%$ was found in the other communities, demonstrating the greater social vulnerability of this population.

Using representative samples of quilombola $(\mathrm{n}=1631)$ and non-quilombola $(\mathrm{n}=1098)$ women from the state of Alagoas, Ferreira et al. ${ }^{22}$ found that among quilombola women, overweight $(50.1 \%$ vs $44.2 \%)$, body fat percentages $>33 \%(37.1 \%$ vs $23.3 \%)$, abdominal obesity (53.5\% vs $34.3 \%$ ), and hypertension (34.9\% vs $11.4 \%$ ) predominated in higher proportions. They concluded that quilombola women had a lower socioeconomic level and were more exposed to risk factors, which makes them more susceptible to morbidity and mortality from CVDs and justifies a prioritized attention by public policies.
Due to precarious living conditions, this population would have difficulties in adopting a healthy lifestyle. Regarding their diet, the consumption of ultra-processed foods, which are rich in sodium and poor in nutrients, may be one of the causes of a high prevalence of hypertension. ${ }^{23}$ In our study, most women with high CVR had SAH.

Corroborating the results of previous studies, in this study we observed a high prevalence of high CVR in smokers and obese individuals, which are conditions that are potentially reversible by a timely approach in primary care. ${ }^{17,24}$

In addition to the risk factors traditionally involved in CVD pathogenesis, it is well known that the racial-ethnic segment investigated by this study faces institutional and personal racism, which constitutes a traumatic event that causes low self-esteem and stress that in turn affect the cardiovascular and hemodynamic conditions and may increase exposure to unhealthy behaviors..$^{25-28}$ Incidentally, a previous study with this population showed a high prevalence $(65.3 \%)$ of common mental disorders. ${ }^{29}$ In the non-quilombola population of Alagoas, this prevalence was $47.9 \% .^{30}$

In Brazil, the "Reorganization Care Plan for Hypertension and Diabetes Mellitus," implemented in 2001, targeted prevention and treatment at the primary health care level. Nevertheless, the identification of CVR 
Table 2 - Prevalence of high cardiovascular risk (CVR) according to the Global Risk Score, based on risk factors for cardiovascular diseases in women $(n=1015)$ from remaining quilombola communities in the state of Alagoas (2018)

\begin{tabular}{|c|c|c|c|}
\hline Variable & n $(\%)$ & High CVR (\%) & PR (CI 95\%) \\
\hline \multicolumn{4}{|l|}{ Classification according to blood pressure $(\mathrm{mmHg})^{\mathrm{A}}$} \\
\hline Optimal BP $(n=410 ; 40.4 \%)+$ normal BP $(n=234 ; 23.0 \%)$ & $644(63.4)$ & 6.5 & 1 \\
\hline Prehypertension (SBP 130-139 and/or DBP 85-89) & $142(14.0)$ & 21.8 & $3.3(2.2-5.1)$ \\
\hline Stage I (SBP 140-159 and/or DBP 90-99) & $157(15.5)$ & 49.0 & $7.5(5.4-10.5)$ \\
\hline Stage II (SBP 160-179 and/or DBP 100-109) & $51(5.0)$ & 70.6 & $10.8(7.7-15.2)$ \\
\hline Stage III (SBP $\geq 180 \mathrm{mmHg}$ and/or DBP $\geq 110$ ) & $21(2.1)$ & 85.7 & $13.1(9.4-18.5)$ \\
\hline Total & $1015(100.0)$ & 20.1 & - \\
\hline \multicolumn{4}{|l|}{ Classification according to glycated hemoglobin $(\mathrm{Hb} A 1 \mathrm{c} \%)^{B}$} \\
\hline Normoglycemia $(<5.7)$ & $381(37.6)$ & 7.9 & 1 \\
\hline Pre-diabetes mellitus (5.7-6.4) & $378(37.3)$ & 14.0 & $1.78(1.2-2.7)$ \\
\hline Diabetes mellitus $(\geq 6.5)$ & $254(25.1)$ & 46.8 & $5.95(4.1-8.6)$ \\
\hline Total & $1013(100.0)$ & 19.9 & - \\
\hline \multicolumn{4}{|l|}{ Classification according to body mass index $\left(\mathrm{kg} / \mathrm{m}^{2}\right)^{\mathrm{C}}$} \\
\hline Low weight $(n=20 ; 2.0 \%)+$ Eutrophic $(n=317 ; 31.2 \%)$ & $337(33.2)$ & 14.2 & 1 \\
\hline Overweight (25-29.9) & $371(36.5)$ & 20.2 & $1.42(1.1-2.0)$ \\
\hline Obesity level I (30-34.9) & $217(21.4)$ & 27.6 & $1.94(1.4-2.7)$ \\
\hline Obesity level II (35-39.9) & $65(6.4)$ & 16.9 & $1.19(0.6-2.2)$ \\
\hline Obesity level III ( $\geq 40$ ) & $25(2.5)$ & 40.0 & $2.81(1.62-4.8)$ \\
\hline Dyslipidemias & $798(78.7)$ & 22.7 & $2.13(1.4-3.2)$ \\
\hline Hypercholesterolemia (LDL $\geq 160$ mg/dL) & $102(10.0)$ & 44.1 & $2.53(2.0-3.3)$ \\
\hline Hypertriglyceridemia (triglycerides $\geq 175$ mg/dL) & $299(29.5)$ & 37.1 & $2.85(2.2-3.6)$ \\
\hline Low HDL (HDL < 50 mg/dL) & $739(72.8)$ & 22.3 & $1.58(1.1-2.2)$ \\
\hline Smoking & $225(22.2)$ & 45.3 & $3.51(2.8-4.4)$ \\
\hline \multicolumn{4}{|l|}{ Age group (years) } \\
\hline 19-39.9 & $577(56.9)$ & 2.2 & 1 \\
\hline $40-49.9$ & $251(24.7)$ & 27.1 & $10.02(6.8-21.4)$ \\
\hline$\geq 50$ & $187(18.4)$ & 65.8 & $29.19(16.9-50.5)$ \\
\hline \multicolumn{4}{|c|}{$\begin{array}{l}\text { PR: prevalence ratio } \\
\text { A Brazilian Guidelines of Arterial Hypertension. }{ }^{1} \text { BP: blood pressure. SBP or DBP: systolic blood pressure or diastolic blood pressure. } \\
{ }^{B} \text { Guidelines of the Brazilian Society of Diabetes } 2017-2018 .{ }^{10} \\
{ }^{C} \text { World Health Organization, } 2000 .{ }^{14}\end{array}$} \\
\hline
\end{tabular}

was limited to the presence of risk factors and/or target organ damage. ${ }^{31}$ Subsequently, it was recommended that CVR assessment be carried out by means of multivariable models, adopting risk identification tools based on the Framingham study. ${ }^{17,32}$

Among the CVR identification methods evaluated in this study, the FRS using the $\mathrm{CP}$ proposed by the Ministry of Health $(\mathrm{CP} \geq 20)$ showed low sensitivity $(18.6 \%)$ but $99.9 \%$ specificity. As mentioned previously, this is not a good performance for a screening instrument, since it results in many false negatives. Based on the ROC curve, we observed that a $\mathrm{CP}$ of 9.0 would result in the highest accuracy. Using this new cutoff resulted in sensitivity and specificity values closer to those observed with the 


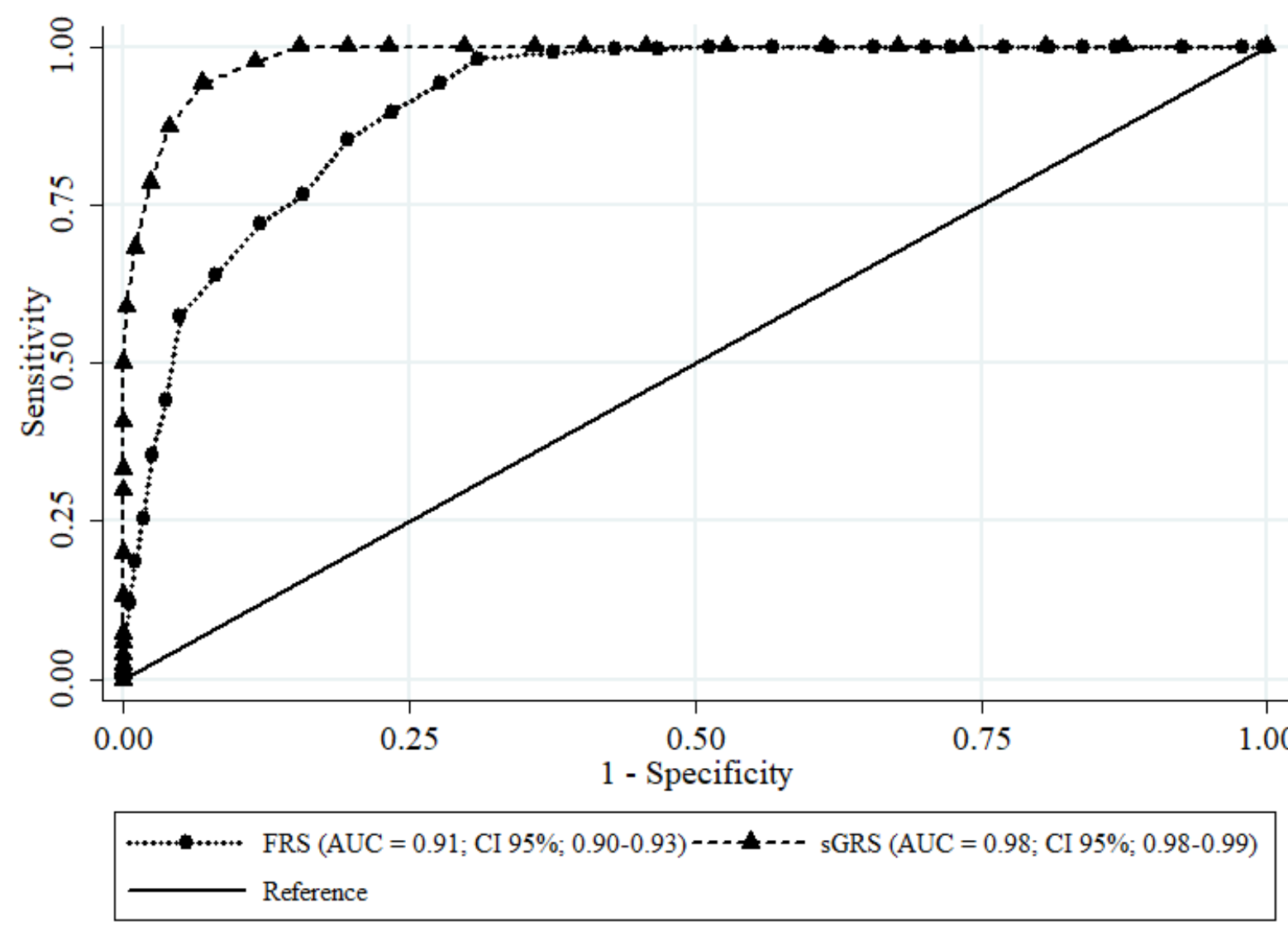

Figure 1 - Areas under the receiver operating characteristic (ROC) curve (AUCs) regarding the ability to predict high cardiovascular risk when using the simplified Global Risk Score (sGRS) or the Framingham Risk Score (FRS), with the Global Risk Score (GRS) as reference. Study with women from remaining quilombola communities in the state of Alagoas, 2018.

Table 3 - Sensitivity (S), specificity (E), and prevalence of high cardiovascular risk (high CVR) obtained according to different cut-off points (CPs) applied to the simplified Global Risk Score (sGRS) and the Framingham Risk Score, with the Global Risk Score as reference. Study with women $(n=1015)$ from quilombola communities in the state of Alagoas, 2018

\begin{tabular}{|c|c|c|c|c|c|}
\hline Score & \multicolumn{2}{|c|}{$\mathrm{CP}$} & $\begin{array}{c}\mathrm{S} \\
(\%)\end{array}$ & $\begin{array}{c}E \\
(\%)\end{array}$ & $\begin{array}{c}\text { High CVR } \\
\text { n (\%) }\end{array}$ \\
\hline \multirow{2}{*}{ sGRS a } & Original $\mathrm{CP}^{\mathrm{a}}$ & 13.0 & 87.2 & 96.0 & $210(20.7)$ \\
\hline & Best $\mathrm{CP}$ c & $11.0^{\mathrm{d}}$ & 97.6 & 88.5 & $292(28.8)$ \\
\hline \multirow{2}{*}{ Framingham Score ${ }^{b}$} & Original $\mathrm{CP}^{\mathrm{b}}$ & 20.0 & 18.6 & 99.0 & $46(4.5)$ \\
\hline & Best $\mathrm{CP}^{\mathrm{c}}$ & $9.0^{\text {ef }}$ & 98.0 & 69.0 & $451(44.4)$ \\
\hline \multicolumn{6}{|c|}{$\begin{array}{l}{ }^{a} D^{\prime} \text { Agostino et al. (2008). }{ }^{3} ; \\
{ }^{b} \text { Ministry of Health (2013). }{ }^{17} \\
{ }^{c} \text { Based on the Youden index. } \\
{ }^{d} \text { Rounded from } 11.5 \text { to } 11.0 \text { to contemplate only integer values, as in the original scale. } \\
{ }^{e} \text { Consolidating the intermediate and high CVR categories to increase sensitivity. } \\
{ }^{f} \text { Rounded from } 8.5 \text { to } 9.0 \text { to contemplate only integer values, as in the original scale. }\end{array}$} \\
\hline
\end{tabular}


sGRS. This index, in turn, would have better accuracy in identifying high CVR in the studied population if the original $\mathrm{CP}(\mathrm{CP} \geq 13.0)$ were to be changed for the one defined in this study $(\mathrm{CP} \geq 11.0)$ because its sensitivity would increase from $87.2 \%$ to $97.6 \%$, although with a reduction in specificity from $96.0 \%$ to $88.5 \%$.

In addition, regarding the low sensitivity observed when using the original cutoff point for the FRS (CP $\geq 20.0$ ), it can be speculated that this is because this protocol was based on a subgroup of atherosclerotic diseases, requiring adjustment to assess CVR in a global scale. This reinforces the relevance of using the sGRS in primary health care. In line with our findings, a study that compared the performance of the GRS and sGRS in predicting CVR in a sample consisting of Black and White Americans ${ }^{33}$ concluded that both indexes found similar results. Therefore, the sGRS may be an alternative for initial screenings aiming at appropriate cardiovascular health care considering cost optimization.

Therefore, the efficient management of CVR depends on the access to health services, qualified professional care, and self-care. ${ }^{34}$ The quilombola communities face political and operational difficulties, since the nearest health services usually have inadequate infrastructure, limited and fragmented care, and few human and material resources. ${ }^{35,36}$ Moreover, the adoption of healthy lifestyle habits also depends on the professional approach, which must consider the peculiarities of these individuals, including their beliefs. ${ }^{34}$

\section{Limitations of the study}

Since this was a cross-sectional study, we worked with prevalence and not incidence. It would be interesting to obtain results from longitudinal studies, in which it would be possible to obtain this parameter according to whether or not the individuals presented high CVR at the beginning of the study.

The representativeness of our results for the state of Alagoas should be regarded with some caution, since the sample calculation used the prevalence of high CVR observed in another state. However, a calculation performed a posteriori, considering our sample size ( $n=1015)$ and the observed prevalence $(20.1 \%)$, indicated a sampling error of $2.3 \%$ ( $0.8 \%$ higher than planned), which is a widely accepted value in population-based epidemiologic surveys.

Another limitation was the fact that we did not analyze CVR in men. This occurred because this study was part of a larger project whose operationalization involved the displacement of researchers to places of difficult access, which were distant from the state capital. Data collection took place during business hours from Monday to Friday, when most of the men in the community were working and, therefore, away from home. Consequently, our male sample was not only small, but also presented many losses, rendering the analysis unfeasible. This suggests the reproduction of this study considering male individuals, since a differential CVR seems to be present between genders.

\section{Final considerations and conclusions}

The prevention of CVD represents a public health challenge, since the development of these diseases involves the exposure to multiple risk factors, many of them closely related to living conditions and habits whose consequences arise in the long term. This is especially worrisome in the population analyzed in this study, considering the precarious conditions in which they live.

This study will contribute to the identification of the most adequate instrument for defining high CVR and classifying the individuals most exposed to the synergism between risk factors, favoring the implementation of measures to reduce CVD morbidity and mortality.

According to the results presented by this study, we conclude that the studied women presented a high prevalence of cardiovascular risk factors and that, in the absence of data on TC and HDL, the sGRS can be used without prejudice as a tool for screening those with high CVR.

\section{Author contributions}

Conception and design of the research: Cavalcante AL and Ferreira HS. Acquisition of data: Cavalcante $\mathrm{AL}$ and Ferreira HS. Analysis and interpretation of the data: Cavalcante AL and Ferreira HS. Statistical analysis: Cavalcante AL and Ferreira HS. Obtaining financing: Ferreira HS. Writing of the manuscript: Cavalcante AL and Ferreira HS. Critical revision of the manuscript for intellectual content: Cavalcante AL and Ferreira HS. First author master's advisor: Ferreira HS.

\section{Potential Conflict of Interest}

No potential conflict of interest relevant to this article was reported. 


\section{Sources of Funding}

This study was partially funded by Conselho Nacional de Desenvolvimento Científico e Tecnológico - CNPq (National Council for Scientific and Technological Development), processes 442063/2014-8 e 466718/2014-4, and Fundação de Amparo à Pesquisa do Estado de Alagoas - FAPEAL (Research Support Foundation of the State of Alagoas), process 60030.000849/2016).

\section{Study Association}

This article is part of the thesis of master submitted by Andressa Lima Cavalcante, from Faculdade de Nutrição da Universidade Federal de Alagoas.

\section{Ethics approval and consent to participate}

This study was approved by the Ethics Committee of the Universidade Federal de Alagoas under the protocol number CAAE $n^{\circ}$ 33527214.0.0000.5013. All the procedures in this study were in accordance with the 1975 Helsinki Declaration, updated in 2013. Informed consent was obtained from all participants included in the study.

\section{References}

1. Barroso WKS, Rodrigues CIS, Bortolotto LA, Mota-Gomes MA, Brandão AA, Feitosa ADM, et al. Brazilian Guidelines of Hypertension - 2020. Arq Bras Cardiol. 2021;116(3):516-658. doi: 10.36660/abc.20201238.

2. Précoma DB, Oliveira GMM, Simão AF, Dutra OP, Coelho OR, Izar MCO, et al. Atualização da Diretriz de Prevenção Cardiovascular da Sociedade Brasileira de Cardiologia - 2019. Arq Bras Cardiol. 2019; 113(4):787-891. doi: 10.5935/abc.20190204.

3. D'Agostino RB Sr, Vasan RS, Pencina MJ, Wolf PA, Cobain M, Massaro JM, et al. General Cardiovascular Risk Profile for Use in Primary Care: The Framingham Heart Study. Circulation. 2008;117(6):743-53. doi: 10.1161/CIRCULATIONAHA.107.699579.

4. National Cholesterol Education Program (NCEP) Expert Panel on Detection, Evaluation, and Treatment of High Blood Cholesterol in Adults (Adult Treatment Panel III). Third Report of the National Cholesterol Education Program (NCEP) Expert Panel on Detection, Evaluation, and Treatment of High Blood Cholesterol in Adults (Adult Treatment Panel III) final report. Circulation. 2002;106(25):3143-421.

5. Oliveira SKM, Caldeira AP. Fatores de Risco para Doenças Crônicas Não Transmissíveis em Quilombolas do Norte de Minas Gerais. Cadernos Saúde Coletiva. 2016;24:420-7. doi: 10.1590/1414-462×201600040093.

6. Barbosa MCL, Barbosa JB, Guerra LFA, Barbosa MFL, Barbosa FL, Barbosa RL, et al. Dyslipidemia and Cardiovascular Risk in AfroDescendants: A Study of the Quilombola Communities in Maranhão, Brazil. Rev. Bras. Med. Fam. Comunidade. 2015;10(36):1-10. doi: 10.5712/ rbmfc10(36)925

7. Alagoas. Secretaria de Estado do Planejamento, Gestão e Patrimônio. Estudo Sobre as Comunidades Quilombolas de Alagoas. Maceió: SEPLAG; 2015.

8. Associação Brasileira de Empresas de Pesquisa (ABEP). Critério de Classificação Econômica Brasil. Alterações na Aplicação do Critério Brasil, Válidas a Partir de 01/06/2019. São Paulo: ABEP; 2019.

9. Segall-Corrêa AM, Marin-León L, Melgar-Quiñonez H, Pérez-Escamilla R. Refinement of the Brazilian Household Food Insecurity Measurement Scale: Recommendation for a 14-item EBIA. Revista de Nutrição 2014;27(2):241-51. doi:10.1590/1415-52732014000200010.

10. Oliveira JE, Foss-Freita MC, Montenegro Junior RM, Vencio S. Diretrizes da Sociedade Brasileira de Diabetes 2017-2018. São Paulo: Editora Clannad; 2017.

11. Faludi AA, Izar MCO, Saraiva JFK, Chacra APM, Bianco HT, Afiune Neto A, et al. Atualização da Diretriz Brasileira de Dislipidemias e Prevenção da Aterosclerose - 2017. Arquivos Brasileiros de Cardiologia. 2017;109(2Supl.1):1-76. doi: 10.5935/abc.20170121.

12. Scartezini M, Ferreira CEDS, Izar MCO, Bertoluci M, Vencio S, Campana GA, et al. Positioning about the Flexibility of Fasting for Lipid Profiling. Arq Bras Cardiol. 2017;108(3):195-7. doi: 10.5935/abc.20170039.

13. Henrique IF, Micheli D, Lacerda RB, Lacerda LA, Formigoni ML. Validation of the Brazilian version of Alcohol, Smoking and Substance Involvement Screening Test (ASSIST). Rev Assoc Med Bras. 2004;50(2):199-206. doi: 10.1590/s0104-42302004000200039.

14. World Health Organization. Obesity: Preventing and Managing the Global Epidemic - Report of a WHO Consultation. Geneva: World Health Organization; 2000.

15. Wilson PW, D'Agostino RB, Levy D, Belanger AM, Silbershatz H, Kannel WB. Prediction of Coronary Heart Disease Using Risk Factor Categories. Circulation. 1998;97(18):1837-47. doi: 10.1161/01.cir.97.18.1837.

16. Brasil. Ministério da Saúde. Cadernos de Atenção Básica n. 14: Prevenção Clínica de Doença Cardiovascular, Cerebrovascular e Renal Crônica. Brasília: Ministério da Saúde; 2006.

17. Brasil. Ministério da Saúde. Cadernos de Atenção Básica n. 37: Estratégias para o Cuidado da Pessoa com Doença Crônica - Hipertensão Arterial. Brasília: Ministério da Saúde; 2014.

18. Matsumoto PM, Barreto ARB, Sakata KN, Siqueira YMC, Zoboli ELCP, Fracolli LA. A Educação em Saúde no Cuidado de Usuários do Programa Automonitoramento Glicêmico. Rev Esc Enferm USP. 2012;46:761-5. doi :10.1590/S0080-62342012000300031.

19. Brasil. Ministério da Saúde. Cadernos de Atenção Básica n. 36: Estratégias para o Cuidado da Pessoa com Doença Crônica - Diabetes Mellitus. Brasília (DF): Ministério da Saúde; 2013.

20. Ferreira HS, Torres ZM. Comunidade quilombola na Região Nordeste do Brasil: Saúde de Mulheres e Crianças Antes e Após sua Certificação. Revista Brasileira de Saúde Materno Infantil. 2015;15:219-29. doi:10.1590/ S1519-38292015000200008.

21. Silva EKP, Medeiros DS, Martins PC, Sousa LA, Lima GP, Rêgo MAS, et al. Food Insecurity in Rural Communities in Northeast Brazil: Does Belonging to a Slave-Descendent Community Make a Difference?. Cad Saude Publica. 2017;33(4):e00005716. doi: 10.1590/0102-311X00005716.

22. Ferreira HS, Silva WO, Santos EA, Bezerra MKA, Silva BCV, Horta BL. Body Composition and Hypertension: A Comparative Study Involving Women from Maroon Communities and from the General Population of Alagoas State, Brazil. Rev Nutr. 2013;26(5):539-49. doi: 10.1590/S141552732013000500005 .

23. Mendonça RD, Lopes AC, Pimenta AM, Gea A, Martinez-Gonzalez MA, Bes-Rastrollo M. Ultra-Processed Food Consumption and the Incidence of Hypertension in a Mediterranean Cohort: The Seguimiento Universidad de Navarra Project. Am J Hypertens. 2017;30(4):358-366. doi: 10.1093/ajh/ hpw137. 
24. Facchini LA, Tomasi E, Dilélio AS. Qualidade da Atenção Primária à Saúde no Brasil: Avanços, Desafios e Perspectivas. Saúde Debate. 2018;42(1):208-23. doi: 10.1590/0103-11042018S114

25. Cuevas AG, Ho T, Rodgers J, DeNufrio D, Alley L, Allen J, et al. Developmental Timing of Initial Racial Discrimination Exposure is Associated With Cardiovascular Health Conditions in Adulthood. Ethn Health. 2019:1-14. doi: 10.1080/13557858.2019.1613517.

26. Paradies Y, Ben J, Denson N, Elias A, Priest N, Pieterse A, et al. Racism as a Determinant of Health: A Systematic Review and Meta-Analysis. PLoS One. 2015;10(9):e0138511. doi: 10.1371/journal.pone.0138511.

27. Williams DR, Priest N. Racismo e Saúde: Um Corpus Crescente de Evidência Internacional. Sociologias. 2015;17(40):124-74. doi: 10.1590/15174522-017004004.

28. Freitas DA, Caballero AD, Marques AS, Hernández CIV, Antunes SLNO. Saúde e Comunidades Quilombolas: Uma Revisão da Literatura. Rev CEFAC. 2011;13(5):937-43. doi: 10.1590/S1516-18462011005000033 .

29. Neiva GS. Saúde Mental Materna e Estado Nutricional do Binômio Mãe/Filho na População Quilombola de Alagoas [dissertation]. Maceió: Universidade Federal de Alagoas; 2010.

30. Barbosa RL. Saúde Mental de Mulheres Segundo a Condição de (In) Segurança Alimentar: Estudo de Base Populacional no Estado de ALAGOAS. 2017. Maceió: Universidade Federal de Alagoas; 2018.
31. Brasil. Ministério da Saúde. Plano de Reorganização da Atenção à Hipertensão Arterial e ao Diabetes mellitus: Manual de Hipertensão Arterial e Diabetes Mellitus. Brasília (DF): Ministério da Saúde; 2001.

32. Brasil. Ministério da Saúde. Prevenção Clínica de Doenças Cardiovasculares, Cerebrovasculares e Renais. Brasília (DF): Ministério da Saúde; 2006.

33. Kariuki JK, Stuart-Shor EM, Leveille SG, Gona P, Cromwell J, Hayman LL. Validation of the nonlaboratory-based Framingham cardiovascular disease risk assessment algorithm in the Atherosclerosis Risk in Communities dataset. J Cardiovasc Med. 2017;18(12):936-45. doi: 10.2459/ JCM.0000000000000583.

34. Foo KM, Sundram M, Legido-Quigley H. Facilitators and Barriers of Managing Patients With Multiple Chronic Conditions in the Community: A Qualitative Study. BMC Public Health. 2020;20(1):273. doi: 10.1186/ s12889-020-8375-8.

35. Gomes KO, Reis EA, Guimarães MD, Cherchiglia ML. Use of health services by quilombo communities in southwest Bahia State, Brazil. Cad Saude Publica. 2013;29(9):1829-42. doi: 10.1590/0102-311X00151412.

36. Vieira ABD, Monteiro PS. Comunidade Quilombola: Análise do Problema Persistente do Acesso à Saúde, sob o Enfoque da Bioética de Intervenção. Saude Debate. 2013;37(99):610-18. 